\title{
O PRINCÍPIO DA FRATERNIDADE E O DIREITO
}

\author{
Thamires Oliveira Feitosa, Pablo Rodrigo França
}

Universidade do Oeste Paulista - UNOESTE, curso de Direito, Presidente Prudente, SP. E-mail: thamires_2009feitosa@hotmail.com

\section{RESUMO}

Este trabalho busca discutir o princípio da fraternidade e a sua efetiva aplicação em todo o direito, como norma ou técnica de hermenêutica. Foi desenvolvido por meio de pesquisas bibliográficas, artigos e a percepção do atual sistema jurídico cujo método de análise pautou-se no hipotético dedutivo, partindo do raciocínio lógico amplo para o mais restrito, com dados coletados e confrontados de maneira dialética, auxiliado pela pesquisa histórica. O mote foi discutir e exaltar a qualidade da fraternidade, ao menos, como direito fundamental de terceira dimensão já consagrado desde a Revolução Francesa. Ainda, no mesmo raciocínio, destacar a vigente Constituição Federal Brasileira que expressamente em seu preâmbulo trouxe a fraternidade como matriz do sistema com o objetivo de incessante busca de uma sociedade justa e livre, com cidadania, paz na solução dos conflitos e amor. Espera-se, por derradeiro, romper paradigmas, com amplos reflexos, em homenagem a justiça humanitária e fraterna.

Palavras-chave: Fraternidade. Direito Fundamental. Princípio. Dimensão. Cidadania.

\section{THE PRINCIPLE OF FRATERNITY AND THE LAW}

\section{ABSTRACT}

This work seeks to discuss the principle of fraternity and its effective application in all law, as a norm or technique of hermeneutics. It was developed through bibliographical research, articles and the perception of the current legal system whose method of analysis was based on the hypothetical deductive, starting from the broad logical reasoning for the most restricted, with data collected and confronted dialectically, aided by historical research. The motto was to discuss and extol the quality of fraternity, at least as a fundamental right of the third dimension already enshrined since the French Revolution. Also, in the same reasoning, highlight the current Brazilian Federal Constitution that expressly in its preamble brought the fraternity as the matrix of the system with the objective of unceasing pursuit of a fair and free society, with citizenship, peace in the solution of conflicts and love. Ultimately, it is hoped to break paradigms, with broad reflexes, in honor of humanitarian and fraternal justice.

Keywords: Fraternity. Fundamental right. Principle. Dimension. Citizenship.

\section{INTRODUÇÃO}

A ideia de fraternidade sempre esteve presente na humanidade com o evidente desejo em tornar o mundo "uma só família", mas, nada obstante nunca teve o verdadeiro reconhecimento. De tal modo, consecutivamente foi esquecida, considerada como sub-princípio, deixando de seguir a mesma estrutura da liberdade e igualdade, todos oriundos da mesma Revolução Francesa. No nosso sistema, inclusive, desde o preâmbulo da vigente Constituição Federal é especialmente exaltada.

A fraternidade acarretou mudanças e transformações nos âmbitos sociais para todos os povos, buscando estar sem qualquer hierarquia e subordinação entre membros de grupos ou 
nações, sendo forma de integralização da humanidade para que ao longo do tempo fosse reconhecida como ideal de filosofia política e social.

Ante ao resumidamente apontado o presente trabalho tem justamente o objetivo de analisar a importância do Princípio da Fraternidade e as ligações existentes, de maneira breve, entre os demais princípios, Liberdade e Igualdade, avaliando a sua estima na tríade da Revolução, onde todos deveriam ocupar o mesmo lugar e grau, apontando ligação com a Dignidade Humana e debatendo de forma clara a valoração desse princípio em razão aos demais, dando a este ênfase como Direito Fundamental de Terceira Dimensão e a necessidade de interpretação de todo o sistema como inerente a esses direitos, com importantes reflexos nas exegeses das normas e decisões, voltadas a sedimentação de uma sociedade de paz social, de aperfeiçoamento da cidadania, justa, livre e fraterna.

Destarte, há a defesa da ampla relevância acadêmica e científica, porquanto, tem sido avaliado como princípio esquecido ou abandonado, o que acaba decorrendo escasso conhecimento sobre o tema, logo, retomar a ideia fundamental é lançar a possibilidade em despertar o desejo do conhecimento, com apontamento de críticas e debates, para a efetivação paulatina deste essencial princípio de manutenção social.

\section{METODOLOGIA}

O presente ensaio foi desenvolvido por meio de diversas pesquisas bibliográficas, leituras, jurisprudências, artigos, inclusive eletrônicos e percepção do atual sistema jurídico aplicado.

A metodologia utilizada, não de maneira exclusiva, diz respeito ao método hipotéticodedutivo, usando a pesquisa histórica como auxiliar. Abordando de forma breve o atual cenário de abandono nas exegeses jurídicas da fraternidade que, conforme será salientado, pertence ao direito inerente e fundamental dos seres humanos.

A pesquisa ousada e respeitosa teve por objetivo descrever e romper paradigmas com o apontamento de que os conflitos sociais devem ser solucionados não visando à simplória declaração de quem tem o direito, contudo, preocupando-se com a construção de uma sociedade efetivamente livre, igual, de justiça concreta e fraterna.

Buscou-se no trabalho a discussão partindo do raciocínio lógico amplo para o mais restrito, com todos os dados coletados confrontados de maneira dialética.

\section{RESULTADO}

Filósofos hodiernos destinaram a exaltar que a Fraternidade é um princípio de categoria jurídica onde se reflete uma novel perspectiva, proporcionando e destacando uma maneira diferente e afetuosa de se compreender a convivência em sociedade. Assim, se princípio é transforma-se em direito, pois, o princípio é exatamente o que fundamenta a existência de um direito e que determina o ato. Portanto, ao lado dos afamados direitos de liberdade e a igualdade, a fraternidade resulta em tentar de maneira pacífica e com o propósito do amor moldar não apenas as atitudes dos seres humanos, buscando mantê-lo dentro de uma única célula de sociedade harmônica, ética e entre irmãos, como também dar técnica e sentido fraterno, de justiça concreta, para as interpretações e criações legislativas.

\section{DISCUSSÃO}

A ideia da fraternidade é uma discussão histórica, pois sempre esteve presente desde as antigas civilizações, com laço de parentesco entre irmãos, irmandade, descendentes de uma mesma família, sendo peça chave para a configuração de cidadania entre os homens (MORAIS; TENORIO, 2014, p.1). 
Vale dizer que há dificuldade em conceituar a fraternidade devido a sua imprecisão, isto é, trata-se de uma categoria com multiplicidade de definições.

"Etimologicamente a fraternidade, deriva do latim fraternitate, confere a ideia de irmandade, do amor ao próximo, da harmonia e da paz" (NICKNICH, 2012, p.173).

Com o surgimento na Revolução Francesa, conhecida como fundadora dos direitos civis, o homem começou a tomar consciência de seu papel na sociedade, consciência essa não limitada aos intelectuais, mas abrangendo também a classe da burguesia. Neste período a ideia de felicidade nasceu como uma meta a ser alcançada por toda a coletividade e não de modo individual. Essa felicidade nasceu como um projeto da sociedade para que exista a possibilidade de que todos que vivam e nela tenham acesso às bases essenciais de sobrevivência, como por exemplo, o ensino, o sustentos, a saúde e outros (COSTA, 2014, p.9).

$\mathrm{O}$ autor por último referenciado continuou a ideia de que para se moldar um novo cidadão de forma igualitária se faz necessário, sinteticamente, a existência de três direitos capazes disto: Liberdade, Igualdade e Fraternidade. Vale ressaltar que essa Liberdade coloca barreiras onde se pode fazer tudo aquilo que não prejudique os demais.

Nas palavras de Pozzoli, aproveitando referência de Antônio Maria Baggio "esses princípios são como uma mesa de três pernas, se um deles vier a faltar, a mesa não se sustenta" (2015, p.4).

É certo que em 1789, quando ocorreu a Declaração dos Direitos do Homem e do Cidadão, junto a Revolução Francesa, ao lado das ideias de Liberdade e Igualdade já estava a Fraternidade proclamada em Assembleia Geral e que emanava em seu artigo I, antes até dos demais: "Todos os seres humanos nascem livres e iguais em dignidade e direitos. São dotados de razão e consciência e devem agir em relação uns aos outros com espírito de fraternidade" (ALMEIDA; APOLINÁRIO, 2011, p.16).

Nesse pensamento Nicknich complementa dizendo (2012, p.172):

A fraternidade, como conceito filosófico, está ligada à liberdade e à igualdade, pois no período da Revolução Francesa, entre maio de 1789 e novembro de 1799, o famoso lema "liberté, egalité, freternité" foi disseminado em busca de um novo Direito influenciado pelos ideais iluministas da Independência Americana ocorrida em 1776.

Diante do exposto constata-se que na tríade "Liberdade, Igualdade e Fraternidade", todas deveriam estar na mesma categoria de dimensão de importância, contudo, isto está longe da realidade, pois, a Fraternidade não ocupou esse importante papel, permanecendo esquecida e abandonada, enquanto a Liberdade e Igualdade assumiram a sua essencialidade de maneira rápida, deixando a fraternidade apenas voltada aos enfoques de assistencialismo e educação, bem longe do âmbito jurídico.

De tal modo nas palavras de Baggio (2008, p.9):

Liberdade e igualdade conhecem, assim, uma evolução que as levou a se tornarem autenticas categorias políticas, capazes de se manifestarem tanto como princípios constitucionais quanto como idéias-força de movimentos políticos. A idéia de fraternidade não teve a mesma sorte.

Continuou o mesmo autor (2008, p.53):

O pensamento moderno desenvolveu a liberdade e a igualdade como categorias políticas, mas não fez mesmo com a fraternidade - embora esta seja o alicerce das outras duas -, seja por fraqueza, por medo das implicações, seja pela eclosão do conflito entre religião e modernidade, que tornou particularmente cheio de obstáculos o terreno da fraternidade. 
No entanto, a fraternidade e o princípio regulador dos outros dois princípios: se vivida fraternalmente, a liberdade não se torna arbítrio do mais forte, e a igualdade não degenera em igualitarismo opressor.

A fraternidade quando ligada ao princípio da dignidade humana, inclusive, dá uma valoração à humanização desse direito de uma forma anarquista, pois, por mais que este direito fraterno esteja presente em culturas e anseios, há dúvidas quanto ao seu grande objetivo na organização jurídica. Desse modo a fraternidade é aplicação necessária para uma melhor convivência e sobrevivência minimamente digna, com reflexos que contribuem para um novo sistema político, onde "o ser humano não deve ser visto apenas como um ser que existe, mas deve ser essencialmente como um ser que vive em sociedade" (POZZOLI; HURTADO, 2015, p.8).

De tal modo nas palavras do professor POZZOLI segundo Resta $(2015$, p.6):

O direito fraterno está estruturado nos seguintes pontos: a lei da amizade; a inimizade, a humanidade, as guerras; constituição sem inimigos; julgar, conciliar, mediar pontos, buscando resgatar a possibilidade de um novo direito, em que a "parente pobre" da Revolução Francesa (a fraternidade) passe a ser a parente rica, solidaria, inclusiva ou simplesmente fraterna.

Conforme ressalvado por muitos filósofos da contemporaneidade, inclusive defendido em diversos trabalhos científicos, a fraternidade está além de um simples princípio, que por muitos foi dado como imêmore, devendo ter o valor de direito fundamental, necessitando ser estudado e praticado, podendo proporcionar diversas mudanças no círculo social, não apenas usado na ótica dogmática como acontece (POZZOLI; HURTADO, 2015, p.5).

Ainda, Lafayette Pozzoli, grande defensor da fraternidade no exato aspecto (2015, p.5):

É preciso apostar em relações baseadas na fraternidade, as quais, realmente, poderiam provocar mudanças substanciais nos mais diversos sistemas sociais, já que esta teria, como base, um conceito não excludente - "a irmandade" - mas uma irmandade sem hierarquia; e não mais a idéia da cidadania, a qual se apresentou, em toda a Idade Moderna, como excludente.

Fernando Gomes de Andrade, sobre o tema e a sua construção histórica, em seu artigo intitulado "Direito de fraternidade como direitos fundamentais de terceira dimensão", frisa com maestria que todas as dimensões são independentes uma das outras e, além disso, que todas se complementam e não abolem as eficácias das demais. Anunciou o autor, fazendo o elo entre todos os direitos $(2011$, p. 8):

É importante frisar que as dimensões de direitos são harmonizadas e não excludentes, para ilustrar a afirmação imaginemos o direito fundamental à vida: o Estado - em condições normais - não pode investir contra a vida de ninguém (direito de defesa, negativo, 1a dimensão), entretanto, para que exista vida é preciso também garantir a saúde (direito prestacional, positivo, 2a dimensão), pois não é inteligível defender a tese que haja pleno respeito pela vida humana sem que exista o oferecimento prestacional do serviço sanitário para assegurá-la e protegê-la; nesse viés observamos a importância devida à construção de hospitais e conseqüente aumento no número de leitos, aparelhamento moderno, médicos suficientes e bem remunerados, distribuição gratuita de medicamentos 
para os indivíduos que não possuam recursos financeiros para adquiri-los, tudo isso promovendo e respeitando a vida, ademais o meio ambiente deve estar equilibrado (direitos difusos, 3a dimensão), pois a poluição e degradação do meio ambiente ameaça à saúde e a vida dos seres humanos.

Desta maneira e diante dos argumentos lançados, todos com fulcro na própria existência das sociedades e povos, é momento tardio, mas, ainda eficaz de assumir a fraternidade como direito fundamental e princípio matriz para a camada jurídica, adotando-a como tendência cogente sistêmica, dando base a sua cognição e propiciando o seu efetivo reconhecimento no mundo jurídico para que a paz, o amor, o aperfeiçoamento e a justiça fraternal prevaleçam nas decisões dos intérpretes e construtores das normas.

\section{CONCLUSÃO}

Os direitos destacados na Constituição Federal, anunciados como fundamentais, possuem proteção dos princípios, desta forma toda e qualquer norma que não convirja com os mesmos nunca existiram com validade ou, se necessário for, são declaradas por ilegítimos.

A ideia de fraternidade foi sendo construída por uma real necessidade de existência ou permanência da humanidade. Na vigente Constituição Federal, desde o início e consagrando o direito fundamental de terceira dimensão, ela é anunciada como diretriz normativa e interpretativa em seu preâmbulo, com o desejo de tornar a sociedade como representantes de uma só família, ou seja, um aglomerado único de seres que devem compatibilizar o entendimento para que as decisões sejam mais justas e humanitárias.

Nesse diapasão, exaltamos neste trabalho o princípio ou direito da fraternidade, fixado na evolução como de terceira geração/dimensão, abandonado ou esquecido por longo período na aplicação, enquanto os demais e mais afamados liberdade e igualdade são enaltecidos, como se os dois últimos não dependessem inteiramente do primeiro para serem efetivados com pureza.

Com a fraternidade se espera que múltiplos paradigmas possam ser rompidos, notadamente quando usados como forma de integralização da humanidade, especialmente nos métodos de hermenêutica quando da aplicação da justiça, com foco e responsabilidade das consequências coletivas de cada decisão, para que seja reconhecida como o ideal de filosofia política e social.

Destarte, é essencial alimentar a fraternidade com proposições e debates críticos, estudos e fomentos, para que ela possa crescer e se desenvolver, assim, naturalmente (como é) será aceito por todos os criadores ou aplicadores do direito como princípio fundamental, buscando a construção de uma real sociedade livre, igual e fraterna, com amor, paz, aperfeiçoamento e justiça concreta.

\section{REFERÊNCIAS BIBLIOGRÁFICAS}

ALMEIDA, G.; APOLINÁRIO, S. Direitos humanos. 2a Edição. São Paulo. Editora Atlas. S.A (2011).

ANDRADE, Fernando Gomes. Direitos de fraternidade como direitos fundamentais de terceira dimensão: aspectos teóricos e aplicabilidade nas decisões do stf brasileiro. Amicus curiae, Santa Catarina, V.8, N8, 1-25, (2011). Disponivel em $<$ http://periodicos.unesc.net/amicus/article/view/570/557 acesso em 17/03/2017

BAGGIO, Antonio Maria(Org.);Pizzolato,Filippo;AQUINI,Marco.(2008). O princípio esquecido. São Paulo, Ed. Cidade Nova. 
BRASIL, Constituição Federal. Atualizada 2007, até a emenda constitucional N 53, de 12/12/2006. Editora Escala.

COSTA, FERNANDO. Revolução Francesa: Liberdade, Igualdade, Fraternidade como Metas Coletivas

Disponível

em

https://fernandonogueiracosta.wordpress.com/2014/01/27/revolucao-francesa-liberdade-

igualdade-fraternidade-como-metas-coletivas/ > acesso em 24 abr.2017.

NICKNICH, MÔNICA. O direito e o princípio da fraternidade (2012), 1-10. Disponível em < http://univille.edu.br/community/revista $r$ du/VirtualDisk.html?action=readFile\&file=artigo14.pdf \&current=/Volume 2 > acesso em 24. Jun. 2017

POZZOLI, L.; HURTADO, A. O princípio da fraternidade nas práticas jurídicas. Marilia (SP), 1-36. Disponível em < http://www.lafayette.pro.br/o-principio-da-fraternidade-150-162-1387/\#comments > acesso em 03 abr. 2017

MORAIS, S; TENORIO, R. Considerações introdutórias sobre as diferenças entre os conceitos de fraternidade e solidariedade (2014) 1-13. Disponível em < http://www.equidade.faced.ufba.br/sites/equidade.oe.faced.ufba.br/files/consideracoes introdut orias sobre as diferencas entre os conceitos de fraternidade e solidariedade silvia morais e robinson tenorio.pdf > acesso em 22 jun. 2017. 